\title{
Kemampuan Gerak Dasar Lari Jarak Menengah Pada Siswa Sekolah Menengah Pertama
}

\section{Basic Movement Skills for Middle Distance Running in Students Junir High School}

\author{
Anak Agung Ngurah Putra Laksana*, I Wayan Adnyana, Kandidus Jimyanto Jenaru \\ Prodi Pendidikan Jasmani kesehatan dan rekreasi, Universitas PGRI Mahadewa Indonesia, Jl. Seroja, Tonja, \\ Kec. Denpasar Utara, Kota Denpasar, Bali, 80235, Indonesia \\ e-mail: agungputralaksana@gmail.com, iwayanadnyana@gmail.com, jhimyjenaru06@gmail.com
}

\begin{abstract}
Abstrak
Penelitian ini bertujuan untuk mengetahui kemampuan gerak dasar lari jarak menengah pada siswa sekolah menengah pertama. Metode penelitian ini adalah kualitatif deskriptif yang dilakukan pada siswa kelas VIII A SMP Widya Sakti Denpasar. Adapun sampel dalam penelitian sebanyak 32 siswa yang berasal kelas VIII A. Teknik pengumpulan data menggunakan triangulasi yaitu observasi, wawancara, dan kuesioner. Analisis data yang digunakan yaitu analisis Miles dan Huberman yaitu analisis data model interaktif yang melalui langkah-langkah pengumpulan data, reduksi data, penyajian data, dan penarikan kesimpulan. Hasil dari observasi diperoleh terdapat siswa pada kategori baik dengan persentase hasil sebanyak 50\% (16 siswa) dan kategori cukup dengan persentase hasil nilai observasi sebanyak 50\% (16 siswa). Hasil data wawancara menunjukkan belum maksimalnya proses pembelajaran karena faktor penghambat. Hasil data kuesioner menunjukkan sebanyak 12 siswa (37,5\%) dalam kategori baik dan sebanyak 20 siswa $(62,5 \%)$ berada dalam kategori cukup. Berdasarkan ketiga sumber data hasil penelitian menunjukkan bahwa belum maksimalnya kemampuan siswa dalam melakukan gerak dasar lari jarak menengah. Penelitian ini dapat dijadikan acuan bagi guru, pelatih serta aktifis olahragawan dalam meningkatkan kemampuan gerak dasar lari yakni dengan koordinasi kondisi fisik serta sarana prasarana.
\end{abstract}

Kata kunci: Kemampuan, Gerak Dasar, Lari Jarak Menengah, Sekolah Menengah Pertama, Kualitatif Deskriptif

\section{Abstract}

This study aims to determine the basic movement ability of middle-distance running in junior high school students. The method of this research is descriptive qualitative which is carried out on students of class VIII A SMP Widya Sakti Denpasar. The sample in this study was 32 students from class VIII A. Data collection techniques used triangulation, namely observation, interviews, and questionnaires. Analysis of the data used is the analysis of Miles and Huberman, namely the analysis of interactive model data through the steps of data collection, data reduction, data presentation, and drawing conclusions. The results of the observations showed that there were students in the good category with the percentage of results as much as 50\% (16 students) and the sufficient category with the percentage of the results of the observation scores as much as 50\% (16 students). The results of the interview data show that the learning process has not been maximized due to inhibiting factors. The results of the questionnaire data showed as many as 12 students (37.5\%) were in the good category and as many as 20 students (62.5\%) were in the sufficient category. Based on the three sources of data, the results of the study indicate that the students' ability to perform the basic movements of middle-distance running is not yet maximal. This research can be used as a reference for teachers, coaches and sports activists in improving the ability to run basic movements, namely by coordinating physical conditions and infrastructure.

Keywords: Basic Movement Ability. Middle Distance Running. Junior High School, Descriptive Qualitatif

corresponding author: agungputralaksana@gmail.com

Artikel Info:

Submitted: 30/08/2021

Revised : 30/09/2021

Accepted : 01/11/2021

Published: 15/11/2021

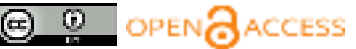

Journal Coaching Education Sports is licensed under a Creatives Commons Attribution 4.0 International License. 


\section{A. Pendahuluan}

Pada hakikatnya pendidikan jasmani adalah proses pendidikan yang memanfaatkan aktivitas fisik (jasmani) dan olahraga untuk menghasilkan perubahan holistic dan kualitas individu, baik dalam hal fisik, mental serta emosional (Haris, 2020). Pendidikan jasmani olahraga dan kesehatan merupakan bagian menyeluruh dari sistem pendidikan yang bertujuan untuk mengembangkan aspek kesehatan, kebugaran jasmani, keterampilan berfikir kritis, stabilitas emosional, olahraga dan kesehatan (Sinulingga \& Pertiwi, 2019). Peranan pendidikan jasmani olahraga dan kesehatan sangat penting yaitu memberikan kesempatan kepada siswa untuk terlihat langsung dalam aneka pengalaman belajar melalui aktivitas jasmani, bermain dan berolahraga yang dilakukan secara sistematis (Widodo, 2018).

Pendidikan jasmani dan olahraga juga merupakan bagian yang tak terpisahkan dari pendidikan umum (Komarruzaman, 2018). Tujuannya untuk membantu anak tumbuh dan berkembang secara wajar sesuai dengan tujuan pendidikan nasional, yaitu menjadi manusia seutuhnya (Widya et al., 2019). Menurut (Pasaribu \& Daulay, 2018) bahwa pencapaian tujuan tersebut berpangkal pada perencanaan pengalamam gerak yang sesuai dengan karakteristik anak sehingga akan meningkatkan kemampuan anak dalam aktifitas gerak.

Kemampuan menurut (Pujianto et al., 2020) adalah tanggung jawab karakteristik yang luas dan stabil untuk kinerja maksimal seseorang pada tugas fisik dan mental. Sedangkan yang dimaksud dengan istilah kemampuan adalah kapasitas seseorang untuk melaksanakan beberapa kegiatan dalam suatu pekerjaan (Pasaribu \& Kurniawan, 2019). Kemampuan fisik berkaitan dengan stamina dan karakteristik tubuh, sedangkan kemampuan intelektual berkaitan dengan aktivitas mental (Kurniawan et al., 2019). Dari beberapa pendapat di atas dapat disimpulkan bahwa kemampuan adalah kecakapan atau kesanggupan yang diperlukan seseorang untuk melakukan kegiatan atau aktivitas secara maksimal pada tugas fisik atau mental.

Kemampuan gerak manusia yang dipengaruhi oleh kondisi sistem-sistem organ dalam, diantaranya adalah sistem neuromuskuler, pernafasan, pencernaan, peredaran darah, energi, tulang, dan persendian (Pasaribu \& Daulay, 2018). Menurut (Bompa, 2011) komponen dasar biomotor olahragawan meliputi kekuatan, kecepatan, ketahanan, koordinasi, fleksibilitas, adapun komponen lain yang merupakan gabungan dari beberapa komponen sehingga membentuk satu 
peristilahan sendiri diantara adalah power dan kelincahan. Menurut (Rahmawati et al., 2019) Power merupakan gabungan dari kekuatan dan kecepatan, sedangkan kelincahan merupakan gabungan dari kecepatan dan koordinasi.

Kondisi fisik atau komponen biomotor yang dimiliki sangat mempengaruhi bahkan menentukan gerak penampilannya. Menurut (Harsono, 2013) dengan kondisi fisik yang baik akan berpengaruh terhadap fungsi dan sistem organisme tubuh. Di antaranya sistem dan organisme dalam tubuh, yaitu sebagai berikut:

a. Daya tahan/Aerobic

Daya tahan adalah kemampuan seseorang untuk melakukan suatu aktivitas dalam waktu yang relatif cukup lama. (Warni et al., 2017). Menurut (Sukadiyanto, 2011) daya tahan dalam olahraga adalah kemampuan peralatan organ tubuh olahragawan untuk melawan kelelahan selama berlangsungnya aktivitas atau kerja. Tujuan latihan ketahan adalah untuk meningkatkan kemampuan olahragawan agar dapat mengatasi kelelahan selama aktivitas kerja berlangsung.

b. Kecepatan/Speed

Menurut (Matitaputty, 2019) kecepatan adalah kemampuan seseorang merupakan kegiatan berpindah tempat dengan waktu yang relatif singkat.
Menurut (Cahyati et al., 2020) Kecepatan (speed) adalah perbandingan antara jarak dan waktu atau kemampuan untuk bergerak dalam waktu singkat. Sedangkan menurut (Sukadiyanto, 2011) kecepatan adalah kemampuan seseorang untuk melakukan gerak atau serangkaian gerak secepat mungkin sebagai jawaban terhadap rangsang. Jadi kecepatan adalah kemampuan seseorang untuk melakukan gerak secara cepat dalam waktu yang sesingkat mungkin.

c. Koordinasi/Coordination

Koordinsi adalah gabungan antara kelincahan dan kecepatan yang dapat menghasilkan gerakan yang selaras, serasi, dan simultan (Handayani, 2018). Menurut (Cahyati et al., 2020) koordinasi adalah kemampuan melakukan gerak pada berbagai tingkat kesukaran dengan cepat dan tepat secara efisien. Menurut (Sukadiyanto, 2011) koordinasi adalah perpaduan dari gerak dua atau lebih persendian yang satu dengan yang lainnya saling berkaitan dalam menghasilkan satu ketrampilan gerak. Dari pendapat ahli diatas, koordinasi merupakan upaya seseorang dalam menyelaraskan kelincahan serta kecepatan dalam satu gerakan.

\section{d. Kekuatan / Strength}

Kekuatan adalah kemampuan dalam menggunakan otot untuk menerima beban 
sewaktu bekerja (Oktariana \& Hardiyono, 2020). Menurut (Sukadiyanto, 2011) kekuatan adalah kemampuan otot atau untuk mengatasi beban atau tahanan. Pegertian secara fisiologis, kekuatan adalah kemampuan neurouskuler untuk mengatasi tahanan beban luar dan beban dalam (Gazali, 2016).

\section{e. Kelentukan / Fleksibilitas}

Kelentukan adalah kemampuan tubuh untuk menggerakan bagian-bagian tubuh dalam suatu ruang gerak yang luas (Candra \& Pasaribu, 2020). Menurut (Sukadiyanto, 2011) fleksibilitas mengandung pengertian, yaitu luas gerak satu persendian atau beberapa persendian. Ada dua macam fleksibilitas, yaitu: (1) fleksibilitas statis, dan (2) fleksibilitas dinamis. Menurut (Cahyati et al., 2020) fleksibilitas adalah kemampuan persendian untuk melakukan gerakan melalui jangka yang luas.

Kemampuan gerak merupakan kemampuan yang dimiliki manusia dan biasa dilakukan utuk berpindah tempat, bahkan ketika dalam kandungan sudah melakukan gerakan yang merupakan fase gerakan reflek (Pasaribu \& Daulay, 2018). Tetapi gerak tersebut harus dilatih, agar kemampuan gerak yang dimiliki semakin baik. Dalam pendidikan jasmani, pengembangan gerak dalam pendidikan jasmani olahraga dan kesehatan dilakukan secara sistematis dari gerak dasar atau 166 gerak sederhana sampai gerak yang lebih kompleks yang biasanya sering digunakan untuk melakukan pemainan dan olahraga (Gunawan et al., 2016).

Gerak dasar merupakan gerak yang bersifat umum dan sering dilakukan. Untuk itu perlu diketahui bahwa keberhasilan siswa dalam belajar gerak ditentukan oleh faktor-faktor lingkungan yang dapat mempengaruhi terjadi perubahan pada diri peserta didik (Kusumawati, 2017). (Erliza, 2018) berpendapat gerak dasar merupakan gerak yang bersifat umum yang apabila dikuasai oleh siswa, akan menjadi landasan yang kukuh untuk dapat mengembangkan gerak-gerak yang lebih kompleks. (Erliza, 2018) juga menjelaskan untuk mengembangkan pengetahuan siswa dalam kemampuan gerak kompleks, maka perlu diberikan banyak kemampuan untuk mengikuti berbagai pengalaman belajar gerak yang baik.

Gerak dasar merupakan gerak yang berkembang sejalan dengan pertumbuhan dan tingkat kematangan pada anak (Setiawan et al., 2020). Gerakan ini pada dasarnya berkembang menyertai gerakan reflek yang telah dimiliki dan disempurnakan melalui proses berlatih yang dilakukan secara berulang-ulang. (Muharram, 2015) menyatakan bahwa kemampuan gerak dasar merupakan kemampuan yang biasa siswa lakukan 
guna meningkatkan kualitas hidup. Gerak dasar adalah bentuk gerakan-gerakan sederhana yang bisa dibagi dalam tiga kategori, yaitu kemampuan locomotor, kemampuan non locomotor dan kemampuan manipulative

Banyak orang mengenal nama olahraga atletik, tetapi tidak mengetahui apa itu sebenarnya olahraga atletik tersebut. Sebenarnya kegiatan yang termasuk dalam dasar atletik biasa dilakukan manusia tiap harinya seperti jalan, lari, melompat dan melempar, tetapi hal tersebut tidak disadari. Seperti halnya yang dikemukakan Muhtar dalam (Gunawan et al., 2016) pada hakekatnya setiap ketangkasan yang dipertunjukan dalam olahraga atletik seperti lari, lempar dan lompat adalah bagian dari gerak atau perbuatan dasar manusia yang terjadi semenjak manusia itu ada.

Atletik yang terdiri dari jalan dan lari dikatakan sebagai cabang olahraga yang paling tua usianya dan disebut juga sebagai "ibu atau induk" dari semua cabang olahraga dan sering juga disebut sebagai Mother of Sports (Dimyati, 2017). Alasannya karena gerakan atletik sudah tercermin pada kehidupan manusia purba. Mengingat jalan, lari, lompat dan lempar secara tidak sadar sudah mereka lakukan dalam usaha mempertahankan dan mengembangkan hidupnya, bahkan mereka menggunakannya untuk menyelamatkan diri dari gangguan alam sekitarnya (Dimyati, 2017).

Dari definisi diatas dapat disimpulkan bahwa atletik adalah aktivitas atau kegiatan jasmani yang meliputi jalan, lari, lompat, dan lempar sebab itu atletik ialah induk dari semua cabang olahraga (mother of sports).

Menurut (Indarto et al., 2018) Pembelajaran atletik di sekolah-sekolah tetap berpedoman pada kurikulum pendidikan jasmani dan kesehatan yang ditetapkan oleh pemerintah. Namun bukan berarti bahwa semua nomor atletik yang tercantum dalam kurikulum tersebut bisa dilaksanakan. Hal tersebut terkait erat dengan sarana dan prasarana yang dimiliki oleh sekolah yang bersangkutan. Banyak guru-guru pendidikan jasmani olahraga dan kesehatan yang hanya bisa mengajarkan satu dua nomor atletik saja dalam satu tahun atau mungkin ada nomor-nomor yang tidak bisa diberikan sama sekali kepada siswanya. Secara umum ruang lingkup pembelajaran atletik di sekolah-sekolah meliputi nomor-nomor: jalan, lari, lompat dan lempar. Pembagian kelompok tersebut adalah sebagai berikut:

1 Nomor jalan meliputi: jalan 5 km, 10 $\mathrm{km}, 20 \mathrm{~km}$ dan $50 \mathrm{~km}$

2 Nomor lari dibagi lagi kedalam : Lari lari jarak pendek meliputi: 100 m, 200 
m, $400 \mathrm{~m}$, Lari jarak menengah meliputi: 800 m, 1500 m, 3000 meter. Lari jarak jauh meliputi: $5000 \mathrm{~m}$, $10.000 \mathrm{~m}$, marathon, Lari estafet meliputi: 4 x 100 m, 4 x 400 m, Lari rintangan meliputi: lari gawang $100 \mathrm{~m}$, $110 \mathrm{~m}, 400 \mathrm{~m}$ dan $3000 \mathrm{~m}$ halang rintang.

3 Nomor lompat meliputi: Lompat jauh gaya jongkok, melayang dan gaya berjalan di udara, Lompat tinggi gaya guling perut, guling sisi dan flop, Lompat jangkit, Lompat tinggi galah.

4 Nomor lempar terdiri dari: Tolak peluru gaya menyamping, belakang dan memutar, Lempar cakram, Lempar lembing dan, Lontar martil.

Lari jarak pendek adalah lari yang menempuh jarak antara $100 \mathrm{~m}$ sampai 400m. Oleh karena itu yang paling penting untuk lari jarak pendek adalah kecepatan. Kecepatan lari jarak pendek merupakan hasil kontraksi yang kuat dan cepat dari otot-otot yang diubah menjadi gerakan halus, lancar dan efisien (Dewi \& Sitompul, 2016).

(Rahmawati et al., 2019) menyatakan salah satu cabang olahraga atletik nomor lari yang jarak minimal yang harus ditempuh pelari yakni 800 meter, 1500 meter dan 3000 meter. (Dimyati, 2017) menyebutkan lari jarak menengah atau yang dalam bahasa inggris lebih kenal middle-distance. Lari jarak menengah membutuhkan penguasaan teknik yang baik karena harus menempuh jarak yang jauh. Lari jarak menengah juga memerlukan kekuatan, kecepatan selain menguasai teknik dengan baik.

Lari Jarak jauh tidak sama dengan Marathon sebab lari jarak jauh terdiri dari beberapa lintasan sedangkan marathon memiliki lintasan sejauh 3000 meter 42,195 km (Pasaribu \& Daulay, 2018). Olahraga ini mengharuskan peserta mengerahkan seluruh energi dan kecepatan sejak start hingga finish, hal ini membuat peserta harus memiliki strategi olah energi agar bisa bertahan (Pasaribu \& Daulay, 2018). Agar bisa menjadi ahli dalam olahraga ini, peserta harus menguasai teknik dasarnya terlebih dahulu (Gunawan et al., 2016).

\section{Teknik Awalan (Start)}

Teknik awalan pada lari jarak jauh mirip dengan lari jarak menengah dengan nomor lari 1.500 meter, yaitu teknik awalan berdiri (Standing Start).

\section{Teknik Berlari}

Pada lari jauh, pelari diharuskan pintar mengelola tenaga/energi dan menjaga keseimbangan tubuh agar peforma kecepatan berlarinya tidak menurun hingga garis akhir (finish).

\section{Teknik Pernapasan}

Saat berlari tubuh memerluan oksigen untuk diserap olah sebab itu pelari harus memahami teknik pernapasan yang benar 
yakni sebagai berikut.

Lari jarak menengah merupakan cabang lari dari olahraga atletik yang memiliki teknik tersendiri untuk melakukannya, jarak tempuh yang cukup panjang yang mengharuskan seorang pelari dapat mengatur stamina, kecepatan serta nafas saat berlari. Lari jenis ini sedikit berbeda dengan lari jarak pendek. Perbedaan mendasarnya ada pada cara kaki menapak pada permukaan lintasan (Suherman, 2016). Cara menapak pada lari jarak menengah yaitu menggunakan ujung kaki tumit dan menolak dengan ujung kaki tersebut, sedangkan pada lari jarak pendek menggunakan ujung kaki, tumit hanya sedikit menyentuh permukaan.

Perbedaan lainya adalah jika lari jarak pendek seorang pelari perlu mengeluarkan tenaga semaksinal mungkin dan lari secepat mungkin ketika lari baru dimulai sampai mendekati garis finish, sedangkan untuk lari jarak menengah seorang pelari harus mampu mengatur secara bertahap agar tidak kelelahan sebelum sampai pada garis finish, karena lintasannya yang cukup panjang (Dewi \& Sitompul, 2016). Lari jarak menengah juga memerlukan kekuatan, kecepatan selain menguasai teknik dengan baik. Lari jarak menengah menempuh jarak 800 meter, 1500 meter dan 3000 meter. Start yang digunakan untuk lari jarak menengah nomor 800 meter adalah start jongkok. Sedangkan untuk jarak 1500 meter menggunakan start berdiri (Dewi \& Sitompul, 2016).

Berdasarkan hasil observasi yang sudah dilakukan di SMP Widya Sakti khususnya kelas VIII A. Terdapat beberapa permasalahan dalam pembelajaran atletik, khususnya materi gerak dasar lari jarak menengah. Berdasarkan latar belakang permasalahan yang telah diuraikan, maka dilakukan penelitian dengan judul "Kemampuan Gerak Dasar Lari Jarak Menengah pada siswa kelas VIII A SMP Widya Sakti Denpasar tahun pelajaran 2019/2020.

\section{B. Metode Penelitian}

Penelitian ini bertujuan untuk mengetahui kemampuan gerak dasar lari pada siswa sekolah menengah pertama. Penelitian ini menggunakan penelitian kualitatif yang bersifat deskriptif, penelitian deskriptif adalah suatu Penelitian yang dilakukan dengan tujuan utama untuk memberikan gambaran atau deskripsi tentang suatu keadaan secara objektif (Herlina \& Suherman, 2020). Penelitian dilakukan di SMP Widya Sakti Denpasar. Sampel yang digunakan terdiri dari 5 siswa dan 1 guru penjaskes untuk wawancara dan 32 siswa untuk observasi dan kuisioner. Teknik pengumpulan data 
yang digunakan adalah teknik triangulasi

berupa observasi, wawancara dan kuisioner.

Pola analisis interaktif yang dikemukakan oleh Miles dan Huberman (Nugrahani et al., 2014) dapat dilihat dalam gambar berikut:

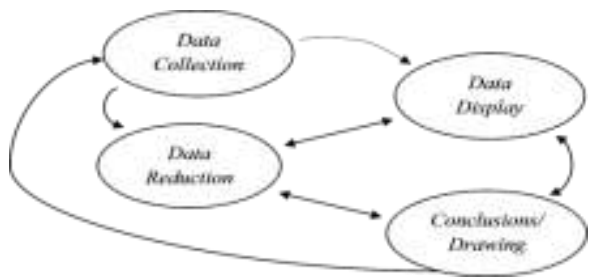

Gambar.3.1. Analisis Data Model

Interaktif (Nugrahani et al., 2014)

\section{Hasil dan Pembahasan}

\section{Hasil}

Sesuai dengan data yang di dapat mulai dari data observasi dengan nilai yang sudah ada data yang didapat bahwa masih terdapatnya siswa dengan nilai yang kurang atau cukup. Kriteria ketuntasan siswa dengan nilai 75 dikategorikan baik, data KKM ini di ambil dari guru penjaskes kelas VIII A SMP WIDYA SAKTI Denpasar. Data nilai dapat dilihat dari tabel yang sudah dibuat sebagai berikut :

\begin{tabular}{|c|l|c|}
\hline No & \multicolumn{1}{|c|}{ Kriteria atau rilai } & Jumlah siswa \\
\hline 1. & $\begin{array}{l}\text { Siswa yang mendanatkan nilai dibawah } \\
\text { KKM 75 }\end{array}$ & 16 siswa \\
\hline 2. & $\begin{array}{l}\text { Sisra yang mendapatkan nilai diatas } \\
\text { KKM 75 }\end{array}$ & 16 sisma \\
\hline & Jumlah & 32 siswa \\
\hline
\end{tabular}

Data nilai di atas yaitu siswa dengan nilai di atas KKM 75 berjumlah 16 siswa dan yang berada di bawah KKM 75 yaitu 16 siswa jika dipersentase sebagai berikut :

\begin{tabular}{|c|c|c|c|c|c|}
\hline No. & $\begin{array}{l}\text { Reutane } \\
\text { Skex }\end{array}$ & Katenori & $\begin{array}{l}\text { Lumials } \\
\text { Sarwa }\end{array}$ & $\begin{array}{l}\text { Dernemtane } \\
\text { Sinwa. }\end{array}$ & Kenamasea Sarwa \\
\hline 1 & $90-100$ & $\begin{array}{l}\text { Seazeat } \\
\text { Bavk }\end{array}$ & D sima & 056 & \multirow{2}{*}{ 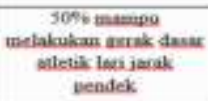 } \\
\hline 2. & $75-60$ & Bauk & 16 suma & 5006 & \\
\hline 3 & $60=74$ & Cukive & 16 aissaca & 500, & \multirow{2}{*}{ 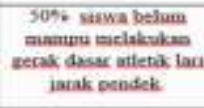 } \\
\hline 4. & $0-39$ & Eutane & Psisma & on; & \\
\hline & \multicolumn{2}{|c|}{ humbas } & $12 \operatorname{sinax}$ & 1004 & \\
\hline
\end{tabular}

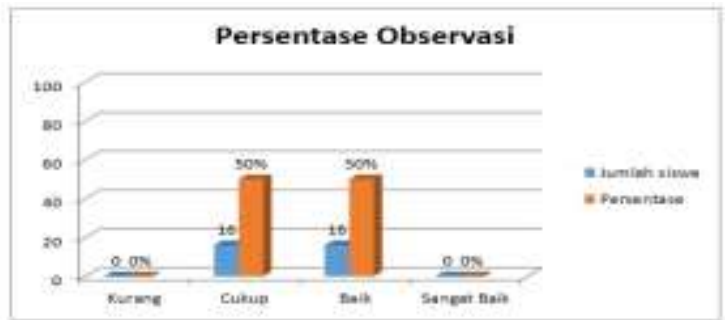

Dari kedua tabel dan diagram diatas dapat dilihat bahwa siswa dengan nilai kemampuan yang berada di bawah KKM yaitu $50 \%$ dan yang berada diatas KKM yaitu $50 \%$ dapat disimpulkan masih terdapat siswa yang memiliki nilai kemampuan kurang atau cukup.

Pada saat wawancara juga dijelaskan oleh siswa dan guru sebagai berikut: Data wawancara dari penelitian dengan 6 informan antara lain 5 siswa kelas VIII A dan 1 guru penjaskes kelas VIII A. Dari data tersebut di dapatkan adanya beberapa faktor penghambat. Pendapat dari informan yaitu belum maksimalnya sarana dan prasarana yg ada dalam proses pembelajaran penjaskes seperti kurangnya alat-alat dalam pembelajaran lari jarak menengah serta lapangan yang tidak rata. 
Dari sarana dan prasarana, guru sudah mampu memanfaatkan sarana dan prasarana yang ada dengan baik. Namun begitu, sarana dan prasarana tetaplah menjadi media untuk menunjang prestasi siswa. Sikap dan perilaku siswa yang kurang baik, juga menjadi penghambat tujuan pembelajaran dan belum maksimalnya tindakan guru dalam menanggulangi masalah perilaku dan sikap siswa yang kurang baik. Bukan hanya faktor penghambat saja, faktor pendukung terdapat antara lain adanya buku lembar kerja siswa (LKS) yang mampu menjadi pegangan siswa untuk belajar dirumah jika tidak mengerti dengan materi yang dijelaskan di lapangan.

Dari data kuesioner juga menunjukan bahwa dari aspek kognitif mereka juga masih ada beberapa siswa yang belum maksimal dalam menjawab soal. Soal yang diberikan ialah kuesioner berupa essay dengan jumlah soal 1 sampai 10, dimana point total dari semua soal itu adalah 100 jadi satu soal memiliki point 10 jika jawaban kurang pas akan di beri point 5 jika siswa salah menjawab akan diberi point 0 , jadi kebanyakan siswa menjawab kuesioner masih kurangnya jawaban pada soal nomer 7,8,dan 9 dimana soal tersebut menanyakan bagaimana sikap teknik dari gerakan atletik lari jarak pendek mulai dari sikap awal, pelaksanaan, dan akhir.
Data dari tabel sesuai dengan data yang di dapat sebagai berikut :

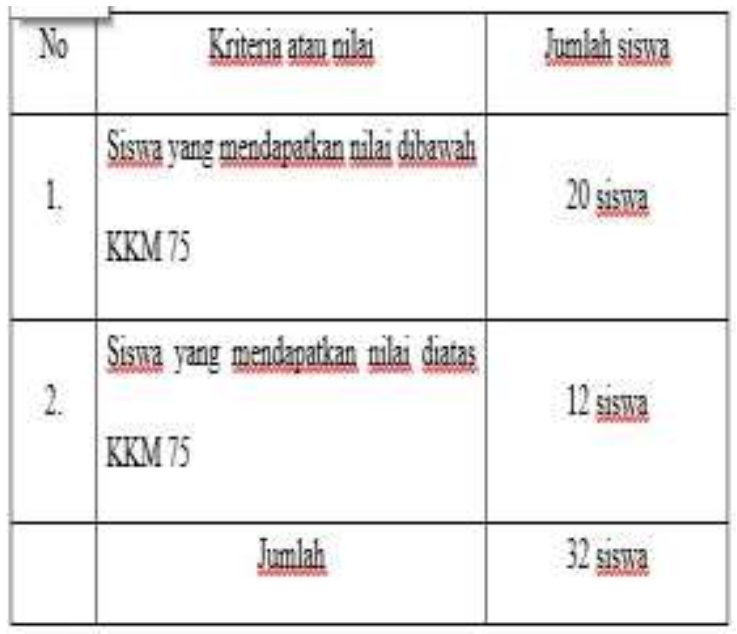

Dari data tabel diatas dapat dilihat siswa yang mendapat nilai di bawah KKM berjumlah 20 siswa dan yang mendapatkan nilai diatas KKM yaitu berjumlah 12 siswa dari data tersebut dapat dilihat persentasenya sebagai berikut :

Berdasarkan data yang diperoleh menunjukkan siswa yang kurang lebih banyak dari yang mendapat nilai diatas atau pas KKM dengan jumlah siswa nilai di bawah KKM yaitu 20 siswa 62,5 \% dan nilai diatas KKM yaitu 12 siswa $37,5 \%$ dapat dilihat masih banyak siswa yang memiliki kemampuan cukup dari aspek kognitif dan itu juga akan berpengaruh kepada keputusan pengambilan gerakan dasar lari jarak menengah.

\section{Pembahasan}

Berdasarkan hasil kuisioner penelitian diketahui terdapat $62,5 \%$ atau sebanyak 20 siswa yang mendapat nilai dibawah KKM dan sebanyak 12 siswa atau sebesar $37,5 \%$ 
yang mendapat nilai diatas KKM. Hasil ini mengindikasi bahwa masih terdapat siswa yang belum mampu melakukan aktifitas gerak dasar pada lari jarak menengah.

Dari hasil observasi terlihat bahwa terdapat 16 siswa atau sebanyak 50\% yang memperoleh nilai dibawah KKM dan 16 siswa juga memperoleh nilai diatas KKM. Dari data observasi menunjukkan bahwa masih terdapat siswa yang kurang mampu dalam melakukan aktifitas gerak dasar pada olahraga lari jarak menengah.

Hasil penelitian yang diperoleh saat wawancara juga memperkuat kedua hasil penelitian sebelumnya yakni dari 6 informan yang telah diwawancara mengatakan bahwa kurang maksimalnya sarana dan prasarana yang ada dalam proses pembelajaran penjaskes seperti kurangnya alat-alat dalam pembelajaran lari jarak menengah serta lapangan yang tidak rata.

Berdasarkan ketiga hasil penelitian yang diperoleh menunjukkan bahwa kemampuan yang dimiliki siswa dalam melakukan gerak dasar lari belum memenuhi kriteria ketuntasan minimal. Hal ini menjadi telaah bahwa banyaknya faktor penghambat yang menjadi dasar kurangnya kemampuan siswa dalam melakukan gerak dasar lari jarak menengah dipengaruhi oleh faktor sarana dan prasarana serta alat-alat penunjang yang belum memenuhi kriteria.

\section{Kesimpulan}

Berdasarkan penelitian yang telah dilakukan yang berfokus pada kemampuan gerak dasar lari jarak menengah pada kelas VIII A SMP Widya Sakti Denpasar belum maksimal. Dari hasil ketiga data obervasi, wawancara dan hasil kuesioner menghasilkan kesamaan data yang kurang maksimal (cukup) dapat dilihat dari data tabel, diagram, dan hasil wawancara diatas. Kemampuan gerak dasar lari jarak menengah pada siswa kelas VIII A SMP Widya Sakti Denpasar dari data observasi ditemukan siswa dengan kategori sangat baik sebanyak 0 siswa (0\%), kategori baik sebanyak 16 siswa (50\%), kategori cukup sebanyak 16 siswa (50\%), kategori kurang sebanyak 0 siswa $(0 \%)$.

Hasil data wawancara menunjukan adanya faktor penghambat suatu proses pembelajaran mengakibatkan kemampuan gerak dasar lari jarak menengah belum maksimal (cukup). Hasil data kuesioner menunjukan data persentase dengan kategori sangat baik sebanyak 0 siswa (0\%), kategori baik sebanyak 12 siswa (37,5\%), kategori cukup sebanyak 20 siswa $(62,5 \%)$, kategori kurang sebanyak 0 siswa $(0 \%)$. Dari proses pembelajaran bahwa masih kurangnya atau cukupnya kemampuan gerak dasar lari jarak menengah siswa kelas VIII A SMP Widya Sakti Denpasar 


\section{Daftar pustaka}

Bompa. (2011). Theory And Of Training

The Key Perpomance,. Hunt

Publishing Company.

Cahyati, S., Kusumawati, I., \& Irianto, D.

P. (2020). Gaya Kepemimpinan

Pelatih Hapkido Daerah Istimewa

Yogyakarta. Journal of Sport and

Health, $\quad$ 1(2), 77-83.

http://ejurnal.mercubuana-

yogya.ac.id/index.php/psikologi/inde

$\underline{\mathrm{X}}$

Candra, J., \& Pasaribu, A. M. N. (2020).

KONTRIBUSI DAYA LEDAK

OTOT TUNGKAI DAN

KELENTUKAN TERHADAP

AKURASI SHOOTING ATLET SSB

TUNAS HARAPAN.

COMPETITOR: Jurnal Pendidikan

Kepelatihan Olahraga, 12(3), 230-

235.

https://doi.org/10.26858/cjpko.v12i3. 16353

Dewi, C. C., \& Sitompul, H. (2016).

Pengaruh Pemberian Umpan Balik

Dan Kemampuan Motorik Terhadap

Hasil Belajar Shooting Siswa Smp

Negeri Dikecamatan Langsa Kota.

Jurnal Teknologi Pendidikan (JTP),

9(1),

14-25.

https://doi.org/10.24114/jtp.v9i1.4888

Dimyati, A. (2017). Pengembangan Model

Permainan Atletik Anak Dalam
Pembelajaran Gerak Dasar Lari Bagi

Siswa Berkebutuhan Khusus

(Tunarungu) Di SLB Negeri

Kabupaten Karawang. Journal Sport

Area, 2(2), 19-26.

https://doi.org/10.25299/sportarea.20

$\underline{\text { 17.vol2(2).1031 }}$

Erliza, Y. (2018). Peningkatan

Pembelajaran Gerak Dasar Renang

Dengan Pendekatan Bermain Siswa

Kelas Iv Sdn 125 Kecamatan

Pekanbaru Kota , Kota. Jurnal

Educhild: Pendidikan Dan Sosial, 7(2), 107-112.

Gazali, N. (2016). Kontribusi Kekuatan

Otot Lengan terhadap Kemampuan

Servis atas Atlet Bolavoli. Journal of

Physical Education, Health and

Sport, $\quad 3(1), \quad 1-6$.

https://doi.org/10.15294/jpehs.v3i1.6

$\underline{496}$

Gunawan, Y. R., Suherman, A., \& Sudirjo, E. (2016). Hubungan Kecepatan Dan Kelincahan Terhadap Kemampuan Dribbling Bola Futsal Pada Atlet O2Sn Kecamatan Sumedang Utara. SpoRTIVE, $\quad 1(1), \quad 1-12$. https://ejournal.upi.edu/index.php/Sp oRTIVE/article/view/3413

Handayani, W. (2018). Hubungan Koordinasi Mata Tangan dan Kekuatan Otot Lengan dengan Ketepatan Hasil Servis Forehand. 
Wahana Didatik, 16(2), 256-266.

https://doi.org/10.31851/wahanadidak tika.v16i2.2052

Haris, F. (2020). Pengaruh Gaya Mengajar Terhadap Keterampilan Gerak Dasar

Siswa Sekolah Dasar Kecamatan

Keranji Padang. Sport Science:Jurnal

Sain Olahraga Dan Pendidikan Jasmani, 20(1), 58-64.

https://doi.org/10.24036/jss.v20i1.40

Harsono. (2013). Coaching dan Aspek-

Aspek Psikologi dalam Coaching.

Dedikbud Dirjen Dikti.

Herlina, H., \& Suherman, M. (2020).

Potensi Pembelajaran Pendidikan

Jasmani Olahraga Dan Kesehatan

(Pjok) Di Tengah Pandemi Corona

Virus Disease (Covid)-19 Di Sekolah

Dasar. Tadulako Journal Sport

Sciences And Physical Education,

$8(1)$,

$1-7$.

http://jurnal.untad.ac.id/jurnal/index.p

\section{$\underline{\mathrm{hp} / \mathrm{PJKR} / \text { article/view/16186 }}$}

Indarto, P., Subekti, N., \& Sudarmanto, E.

(2018). Pengukuran Tingkat Minat dengan Bakat Mahasiswa Pendidikan

Olahraga Universitas Muhammadiyah

Surakarta. JSES : Journal of Sport and Exercise Science, 1(2), 57. https://doi.org/10.26740/jses.v1n2.p5 $\underline{7-61}$

Komarruzaman, A. (2018). Pembelajaran

Gerak dasar dalam pembelajaran Pendidikan jasmani, olahraga , dan kesehatan di sekolah dasar melalui Permainan. Prosiding Seminar Dan Diskusi Nasional Pendidikan Dasar 2018, 254-258.

Kurniawan, E. Y., Kesoema, T. A., \& Hendrianingtyas, M. (2019). Pengaruh Latihan Fleksi Dan Ekstensi Lumbal Terhadap Fleksibilitas Lumbal Pada Dewasa Muda. Diponegoro Medical Journal (Jurnal Kedokteran Diponegoro), 8(1), 161-170. https://doi.org/10.14710/dmj.v8i1.233 $\underline{14}$

Kusumawati, O. (2017). Pengaruh Permainan Tradisional Terhadap Peningkatan Kemampuan Gerak Dasar Siswa Sekolah Dasar Kelas Bawah. Jurnal Pendidikan Dan Pembelajaran Dasar, 4, 124-142. https://doi.org/10.24042/terampil.v4i2 .2221

Matitaputty, J. (2019). Pengaruh Latihan Kecepatan Terhadap Kecepatan Menggiring Bola Pemain Futsal Junior Fc Patriot Penjaskesrek Unpatti Ambon Johanna. Jurnal Ilmiah Wahana Pendidikan, 5(2), $101-113$

https://doi.org/10.5281/zenodo.27818 $\underline{01}$

Muharram, N. A. (2015). Pengaruh Pembelajaran dan Kemampuan Gerak Dasar Terhadap Peningkatan http://ejurnal.ubharajaya.ac.id/index.php/JCESPORTS 
Kemampuan Sprint 100 Meter. Jurnal

Sportif, $\quad 1(1), \quad 22-31$.

https://doi.org/10.29407/js_unpgri.v1i

$\underline{1.572}$

Nugrahani, Farida, \& Hum, M. (2014).

Metode Penelitian Kualitatif. Cakra

Books.

Oktariana, D., \& Hardiyono, B. (2020).

Pengaruh Daya Ledak Otot Lengan,

Daya Ledak Otot Tungkai Dan

Kekuatan Otot Perut Terhadap Hasil

Smash Bola Voli Pada Siswa SMK

Negeri 3 Palembang. Journal

Coaching Education Sports, 1(1), 13-

24.

https://doi.org/10.31599/jces.v1i1.82

Pasaribu, A. M. N., \& Daulay, D. E.

(2018). Pengaruh Permainan Lari

Estafet terhadap Kemampuan Gerak

Dasar Motorik Kasar Siswa Kelas 3

SDN Karet II Kabupaten Tangerang.

Jurnal Prestasi, 2(4), 9-14.

https://doi.org/10.24114/jp.v2i4.1190

$\underline{9}$

Pasaribu, A. M. N., \& Kurniawan, F. (2019). Hubungan Kekuatan Tungkai dan Koordinasi Mata Kaki dengan

Kemampuan Menggiring Bola dalam

Permainan Sepakbola pada

Mahasiswa Pendidikan Kepelatihan

Olahraga FIP Ubhara Jaya.

COMPETITOR: Jurnal Pendidikan

Kepelatihan Olahraga, 11(1), 1-7. https://doi.org/10.26858/com.v11i1.1

$\underline{3380}$

Pujianto, D., Sutisyana, A., Arwin, A., \& Nopiyanto, Y. E. (2020). Pengembangan Model Latihan Passing Sepakbola Berbasis Sasaran Teman. Journal Coaching Education Sports, $\quad 1(1), \quad 1-12$. https://doi.org/10.31599/jces.v1i1.81 Rahmawati, I., Sujiono, B., \& Marani, I. N. (2019). Hubungan Antara Panjang Tungkai Dan Daya Ledak Otot Tungkai Terhadap Hasil Lari 100 Meter Atlet Atletik. Jurnal Ilmiah Sport Coaching and Education, 3(3).

Setiawan, A., Yudiana, Y., Ugelta, S., Oktriani, S., Budi, D. R., \& Listiandi, A. D. (2020). Hasil Belajar Pendidikan Jasmani dan Olahraga Siswa Sekolah Dasar: Pengaruh Keterampilan Motorik (Tinggi) dan Model Pembelajaran (Kooperatif). TEGAR: Journal of Teaching Physical Education in Elementary School, 3(2), 59-65. https://doi.org/10.17509/tegar.v3i2.24 $\underline{513}$

Sinulingga, A., \& Pertiwi, D. (2019). Profesionalisme guru pendidikan jasmani dari kepemimpinan kepala sekolah, budaya sekolah hingga motivasi kerja guru. Jurnal SPORTIF : Jurnal Penelitian 
Pembelajaran, 5(2), 296-311. https://doi.org/10.29407/js_unpgri.v5i 2.13113

Suherman, A. (2016). Pengaruh Penerapan Model Kooperatif Tipe Jigsaw Dan Tgt (Teams Game Tournament) Terhadap Keterampilan Sosial Dan Keterampilan Bermain Bolavoli. Jurnal Pendidikan Jasmani Dan Olahraga, $\quad$ 1(2), 8. https://doi.org/10.17509/jpjo.v1i2.565 $\underline{9}$

Sukadiyanto. (2011). Pengantar Teori Dan Metodologi Melatih Fisik. Lubuk Agung.

Warni, H., Arifin, R., \& Bastian, R. A. (2017). Pengaruh Latihan Daya Tahan (Endurance) Terhadap Peningkatan Vo2max Pemain Sepakbola. Multilateral: Jurnal Pendidikan Jasmani Dan Olahraga, $16(2)$, 121-126.

https://doi.org/10.20527/multilateral.v $\underline{16 \mathrm{i} 2.4248}$

Widodo, A. (2018). Makna Dan Peran Pendidikan Jasmani Dalam Pembentukan Insan. Jurnal Motion, 9(1), 53-60.

https://www.researchgate.net/publicat ion/329442726_MAKNA_DAN_PE RAN_PENDIDIKAN_JASMANI_D ALAM_PEMBENTUKAN_INSAN YANG_MELEK_JASMANIAHTER -LITERASI_JASMANIAHNYA
Widya, A. D. I., Pendidikan, J., \& Volume, D. (2019). Fungsi dan Tujuan Pendidikan. ADI WIDYA: Jurnal Pendidikan Dasar, 4(1), 2939.

https://doi.org/10.25078/aw.v4i1.927

.

